\title{
0 Centro de Treinamento de Pessoal do Estado do Paraná e a capacitação e aperfeiçoamento do professor
}

\author{
The Staff Training Center of Paraná State and \\ its teacher training and development
}

El Centro de Entrenamiento Personal del Paraná y la formación docente y desarrollo del profesor

REGINALDO RODRIGUES DA COSTA (Da

\section{Resumo}

0 presente texto pretende apresentar as ações desenvolvidas pelo Centro de Seleção, Treinamento e Aperfeiçoamento de Pessoal do Paraná - CETEPAR, durante o período de 1971 a 1982. Ao propor este objeto de pesquisa acredita-se que as informações históricas sobre a capacitação desses professores podem completar lacunas da história da educação paranaense e permitem compreender os problemas apresentados atualmente na educação paranaense. 0 que se apresenta neste texto é apenas um recorte de um estudo maior, de doutoramento, que tem como objeto as ações de aperfeiçoamento e capacitação de professores que ensinavam matemática que foram desenvolvidas pelo governo do Estado do Paraná durante o período de 1961 até 1982.

Palavras-chave: CETEPAR. Treinamento. Capacitação. Aperfeiçoamento. Política Estadual.

\begin{abstract}
This paper intends to present the actions undertaken by the Centre for Training and Selection of staff of Paraná -CETEPAR - during the period from 1961 to 1982. When proposing this research subject we believe that the historical information about the training of these teachers can fill gaps in the history of Paraná's education, which allows us to understand the problems currently presented in Paraná's education. What is presented in this text is only an excerpt of a larger, doctoral study, which has as its object the improvement actions and training of teachers who taught mathematics which were developed by the government of the State of Paraná during the period from 1961 to 1982.
\end{abstract}

Keywords: CETEPAR. Training. Improvement. State Policy.

\footnotetext{
a Pontifícia Universidade Católica do Paraná (PUCPR), Curitiba, PR, Brasil. Doutor em Educação, e-mail: reginaldo.costa@pucpr.br
} 


\section{Resumen}

Este documento tiene la intención de presentar las acciones llevadas a cabo por el Centro de Formación y Selección y Formación de Personal de Paraná - CETEPAR durante el período de 1971-1982. Al proponer este tema de investigación yo creo que la información histórica sobre la formación de estos profesores puede completar las lagunas de la historia de la educación del Paraná, y que nos permiten comprender los problemas que actualmente se presentan en la educación del Paraná. Lo que se presenta en este texto es sólo un extracto de un estudio más amplio, de doctorado, que tiene por objeto las acciones de mejora y capacitación de los profesores que enseñaban matemáticas que fueron desarrolladas por el gobierno del Estado de Paraná durante el período 1961-1982.

Palabras clave: CETEPAR. Entrenamiento. Formación. Mejora. Política de Estado.

\section{Introdução}

O estudo apresentado neste texto se refere ao papel desempenhado pelo Centro de Seleção, Treinamento e Aperfeiçoamento de Pessoal do Paraná (CETEPAR), que foi criado em 1969 para, inicialmente, cumprir com a função de "treinar" os professores que atuavam no Ensino Primário do Estado do Paraná. A orientação teórico-metodológica deste estudo apoia-se na historiografia e na história cultural.

Para a realização deste estudo foi preciso clarear os rumos metodológicos necessários para a constituição das ações do CETEPAR relativas à capacitação e aperfeiçoamento docente. É oportuno ressaltar que a pesquisa histórica não intenciona repetir, compilar ou reconstruir, mas produzir um conhecimento histórico a partir da percepção da realidade existente (FÉLIX, 1998). Segundo Valente (2005a, p. 4):

Os fatos históricos são constituídos a partir de vestígios, de rastros deixados sobre esses traços no presente pelo passado. Assim o trabalho do historiador consiste em efetuar um trabalho sobre esses traços para construir os fatos. Desse modo, um fato não é outra coisa senão o resultado de uma elaboração de um raciocínio, a partir das marcas do passado, segundo as regras de uma crítica. Mas, a história que se elaborar não consiste tão simplesmente na explicação dos fatos.

A abordagem histórica não é uma simples narração factual dos fenômenos, mas um processo de “identificação e construção de fontes” (VALENTE, 2005b, p. 6), 
que será tratado pelo historiador para responder suas interrogações que permitirão avançar no campo da ciência.

Lopes (1995, p. 43-44), parafraseando Antoine Leon, aponta as contribuições de um trabalho historiográfico:

Considera a abordagem histórica dos fatos da educação um indispensável instrumento de análise das situações do presente, devido à preocupação em relativizar os problemas atuais. Considera-a ainda como uma fase preliminar da ação, ao evidenciar a ambigüidade de todas as inovações, ao apontar os conflitos que pontuam todo o processo evolutivo e ao introduzir a exigência de longo prazo na avaliação dos efeitos educacionais.

O campo de investigação da História da Educação Matemática focaliza sua atenção às pesquisas que pretendem explicar e orientar as diferentes formas de aprendizagem e conhecimento matemático, bem como as novas tendências no ensino desta ciência. Estudos deste campo científico já mostraram que o processo de ensino e de aprendizagem matemática está cheio de elementos que, quando conhecidos e expostos, tornam-se instrumentos norteadores da prática educativa em matemática.

Preocupou-se com esta pesquisa, além de apontar quais foram os cursos de aperfeiçoamento desenvolvidos durante o período compreendido, descrever os mecanismos produtores de conhecimento sobre a capacitação docente entendida e pretendida pelo governo do Estado do Paraná. A intenção foi de trazer aos nossos olhos a forma como a capacitação foi proposta pelos órgãos oficiais.

As fontes utilizadas neste estudo foram encontradas no arquivo "morto" do CETEPAR, atualmente denominado Diretoria de Tecnologias Educacionais. Nesse arquivo foi possível encontrar os livros de registros dos participantes de cursos promovidos e também materiais didáticos produzidos e utilizados pelo CETEPAR entre os anos de 1971 e 1982. Por meio desses documentos e fontes, foi possível obter informações sobre os cursos desenvolvidos, o contingente de professores, a abrangência geográfica dos participantes da capacitação e aperfeiçoamento e os saberes contemplados na formação desenvolvida pelo governo paranaense à época. Também foram utilizados relatórios da Secretaria de Educação do Paraná onde são descritas as atividades realizadas pelo CETEPAR nos períodos de 1973 a 1974, de 1975 a 1977 e nos anos de 1979 a 1983. Informações sobre as alterações e mudanças 
do ensino regular estadual entre o período de 1971 a 1980, organizadas pela Fundação de Apoio a Educação Paranaense - FUNDEPAR, foram consideradas neste estudo.

A periodização dessa pesquisa tem início no ano de 1971, momento de promulgação da Lei no 5692/71 que estruturou o sistema de ensino que passava a ter o $1^{\circ}$ e $2^{\circ}$ graus. Durante esse período o estado do Paraná contou com a permanência de quatro governadores no poder: Pedro Viriato Parigot de Souza inicia seu mandato em novembro de 1971 e encerra em julho de 1973; Emílio Hoffmann Gomes assume de agosto de 1973 a março de 1975; Jayme Canet Júnior assume o governo estadual em março 1975 termina seu mandato em março de 1979; Ney Braga governa a partir de março de 1979 e finaliza seu mandato em maio de 1982.

O Estado do Paraná tem um entrosamento afinado com a política federal, e suas ações de implantação e reformas de ensino seguiram basicamente o que versavam as leis instituídas. A análise dos relatórios revela um discurso em que as realizações efetuadas assumiam proporções sem precedentes, que, no entanto, não foram suficientes para minimizar os problemas relacionados com a atuação e o aperfeiçoamento dos professores daquela época.

\section{O CETEPAR e sua relação com o aperfeiçoamento e capacitação do professorado paranaense}

O CETEPAR foi criado pelo Decreto no 15.729 em 1969 no governo de Paulo Pimentel. Denominado à época Centro de Treinamento do Magistério Primário, no ano de 1971 passa ser chamado Centro de Seleção, Treinamento e Aperfeiçoamento de Pessoal do Paraná e integra um conjunto de instituições subordinadas à Secretaria de Educação e Cultura, que por meio do Centro de Estudos e Pesquisas Educacionais tinha como função definir os encaminhamentos necessários para a atuação e exercício do magistério paranaense.

Com a Reforma do Ensino estabelecida pela Lei no 5.692/71, o planejamento de ações e sua avaliação estatística eram caminhos tecnicamente definidos e considerados indispensáveis a se atingir os objetivos estabelecidos para a reforma que organizou o ensino em dois níveis: o Ensino de $1^{\circ}$ Grau que era constituído por oito 
séries (de $1^{\mathrm{a}}$ a $8^{\mathrm{a}}$ séries) e o Ensino de $2^{\circ}$ Grau que, dependendo da habilitação, poderia durar três ou quatro anos.

As ações para garantir a reforma pretendida pela lei foram descentralizadas e regionalizadas, ou seja, foram estabelecidas etapas com a intenção de cobrir todo o espaço geográfico e o contingente de professores. Para isso houve uma reestruturação da Secretaria de Educação bem como a criação de diretorias e departamentos específicos para cada grau de ensino $\left(1^{\circ}\right.$ e $2^{\circ}$ Graus $)$ e também para as modalidades (Educação Especial, Educação Complementar). O CETEPAR estava vinculado à Diretoria de $1^{\circ}$ e $2^{\circ}$ Graus, mas, ao mesmo tempo, era um órgão executor das atividades planejadas para a Educação Especial e Educação Complementar.

A função do CETEPAR era de selecionar professores para atuar nas escolas paranaenses, mas no período que compreende este estudo sua atribuição estava diretamente relacionada com a capacitação de professores e também do pessoal técnico administrativo que atuava nas escolas paranaenses. Para isso o CETEPAR (COSTA, 2012) desenvolvia três atividades: a capacitação, o aperfeiçoamento e a assistência ao ensino.

A primeira atividade considerava que na época muitos professores eram leigos e deveriam ser habilitados para continuarem atuando no magistério paranaense. Já o aperfeiçoamento era destinado aos professores que atuavam nos dois graus de ensino e nas modalidades da Educação Especial e no Ensino Supletivo, e a assistência se referia à elaboração de materiais que pudessem subsidiar o ensino dos professores nas escolas e, principalmente, fundamentar e orientar os professores para a reforma prevista na Lei ${ }^{\circ}$ 5.692/71.

A atuação do CETEPAR, na época, incluía o estabelecimento de normas e orientações para o desenvolvimento do pessoal do sistema estadual de ensino. Para as diretrizes desse órgão era imprescindível que os professores tomassem conhecimento dos objetivos e princípios expressos pela Lei no $5.692 / 71$. Para isso, a atuação desse órgão durante o período de 1971 a 1982 superou qualquer outra ação de capacitação e aperfeiçoamento, não só pelo contingente de professores que foram alcançados pela capacitação e aperfeiçoamento, mas também pela elaboração e veiculação de material disponibilizado aos professores na época (COSTA, 2012). 
Para atingir seus objetivos o CETEPAR passou a elaborar e executar uma estratégia que se utilizou da formação de multiplicadores oriundos das mais diversas regiões do estado para realizar a capacitação e o aperfeiçoamento em suas localidades. Esses multiplicadores realizavam um curso intensivo nas dependências do CETEPAR, localizado na cidade de Curitiba, capital do Estado do Paraná, e, ao retornarem para sua região, desenvolviam os cursos pensados e elaborados para a implantação da reforma de $1^{\circ}$ e $2^{\circ}$ graus. Durante o período de 1971 a 1982 a capacitação e o aperfeiçoamento atingiram um total de 102.255 professores que atuavam no Ensino de $1^{\circ}$ Grau e 6.608 professores do Ensino de $2^{\circ}$ Grau (FUNDEPAR, 1982).

Pela análise quantitativa é possível inferir que as ações de capacitação e de aperfeiçoamento desenvolvidas na época tiveram maior incidência e concentração sobre o contingente de professores que atuavam no Ensino de $1^{\circ}$ Grau do que aquelas destinadas aos professores que atuavam no Ensino de $2^{\circ} \mathrm{Grau}$. Um outro aspecto a ser explicitado se refere aos municípios paranaenses que foram contemplados com as ações do CETEPAR (COSTA, 2012): inicialmente os cursos foram desenvolvidos em municípios mais populosos, enquanto aqueles que tinham uma quantidade inexpressiva de habitantes foram deixados para as últimas etapas do processo de implantação da reforma do ensino.

Mas é preciso destacar que as ações de capacitação desenvolvidas ao longo dos anos do período deste estudo não seguiram uma proporcionalidade ou uma manutenção. Podemos observar que a cada novo governo que assumia havia uma variação dessas ações, fossem elas para uma maior parcela de professores e municípios ou para uma redução significativa dessas categorias. Uma hipótese: essas alterações se devem ao fato de ocorrer um entrosamento maior ou menor entre o governo paranaense e o governo federal, o que pode justificar essas alterações e diferenças nas atividades de capacitação e de aperfeiçoamento dos professores paranaenses. Ao analisar os dados expressos nos relatórios da SEC (PARANÁ, 1977; 1983), essa hipótese se confirma uma vez que podemos observar que nos governos de Jayme Canet Junior (1975 a 1979) e Ney Braga (1979 a 1982) as atividades do CETEPAR aumentam significativamente e a explicação pode ser esse entrosamento que deu continuidade à capacitação e aperfeiçoamento de professores no estado do Paraná. 


\section{Cursos realizados pelo CETEPAR: 1971-1982}

Para apresentação dos cursos desenvolvidos foram necessárias a ordenação e a reordenação que exigiu a cópia e reescrita dos documentos que forneceram vestígios sobre as ações do CETEPAR. O ato de produzir tais informações desfigurou os documentos que serviram para "preencher lacunas de um conjunto" (CERTEAU, 1988, p. 81).

As fontes utilizadas nos forneceram várias evidências de que as ações de capacitação e aperfeiçoamento vislumbravam atingir seus objetivos quanto à reforma que reorganizava o ensino, apropriação da Lei $n^{0} 5.692 / 71$. Os traços e vestígios encontrados nessas fontes permitem afirmar que o foco estava principalmente em atingir as séries iniciais, ou seja, fazer incidir as concepções sobre os professores que tinham maior contingente de alunos, que eram aqueles que frequentavam o Ensino de $1^{\circ}$ Grau.

Percebe-se uma preocupação do governo paranaense em ampliar a relação entre o meio urbano e o meio rural; suas ações são expressivas em relação a essa realidade quando propõem tanto uma ampliação da estrutura física das escolas rurais quanto o aumento do número de docentes para as escolas dos distritos e da zona rural. As ações foram também relativas ao ajustamento e revisão dos currículos escolares quanto às necessidades específicas de cada contexto.

\section{Cursos destinados aos professores da educação pré-escolar}

Os cursos destinados aos professores que atuavam na Pré-Escola só ocorreram a partir de 1976. Acreditamos que isso se deva ao fato de a Reforma de Ensino do $1^{\circ}$ Grau preocupar-se inicialmente com a implantação da $1^{\mathrm{a}}$ e $5^{\mathrm{a}}$ séries: a primeira para inserir a criança de sete anos no processo educacional, e a segunda pelo fato de dar continuidade aos estudos para alunos de onze anos que pretendiam chegar à $8^{\mathrm{a}}$ série com quatorze anos de idade. 
A organização dos cursos para este nível de ensino foi bem diversa e a carga horária variou de quarenta horas até novecentas e vinte horas. Da mesma forma, os conteúdos desenvolvidos eram amplos e se referiam às áreas a serem trabalhadas na pré-escola. Os fundamentos objetivavam o desenvolvimento socioemocional e perceptivo da criança, além da exploração corporal e raciocínio lógico-matemático que indicam atividades com quantificação, correspondência, noção de conjunto, elemento e pertinência, números e numerais, operações, atividades com blocos lógicos. Quanto à alfabetização, foram abordadas técnicas e também um modelo inspirado nas orientações do professor Erasmo Piloto para abordar os conteúdos com significado ao contexto e à realidade do aluno.

\section{Cursos de aperfeiçoamento e capacitação para professores do ensino de $1^{\circ}$ grau}

Os cursos para professores que atuavam no Ensino de $1^{\circ}$ Grau foram planejados tecnicamente, no sentido de atender, inicialmente, um maior número de professores. Assim, durante o período de 1971 a 1976 foram desenvolvidos em seis etapas: em 1971 ocorreu um seminário divulgando a Lei no 5.692/71 e outro encontro para explanação da forma de expansão das etapas da reforma para chefes de núcleos de educação, diretores e secretários de escola; em 1972 os cursos foram realizados em nove municípios que possuem Núcleo Regional de Educação (esses municípios tinham juntos um número de habitantes superior a $40 \%$ da população paranaense); em 1973 os cursos abrangeram trinta e sete municípios que possuíam uma população superior a 10 mil habitantes; em 1974 trinta e sete cidades que possuíam 5 mil habitantes; em 1975 os cursos foram realizados em oitenta e setes cidades com uma população entre 2 mil e 5 mil; por fim, cento e vinte cidades e distritos rurais com população inferior a 2 mil habitantes, em 1976, foram contemplados com os cursos (COSTA, 2012).

O curso também apresentava etapas, sendo a primeira a divulgação e explicitação das concepções que fundamentavam a reforma do ensino. Essas concepções enfatizavam a importância do planejamento do ensino por parte dos 
professores e também destacavam a organização do ensino utilizando projetos de ensino, ou seja, o professor teria que estruturar sua ação docente empregando técnicas de problematização e estudos dirigidos. Ao fim das quatro etapas o professor, para demonstrar a apropriação desse ideário, deveria apresentar um projeto que tivesse sido elaborado no âmbito da capacitação que se desenvolvia durante o ano todo, aplicar e apresentar os resultados nas últimas etapas do curso de aperfeiçoamento.

Como forma de subsidiar o trabalho desses professores, tanto na capacitação e aperfeiçoamento como no trabalho realizado na escola, o CETEPAR, a partir de 1974, elabora e passa a divulgar, nesses cursos, as Diretrizes Curriculares para Docentes e Diretores para o Ensino de $1^{\circ}$ Grau. Vale ressaltar que o que diferenciava uma diretriz de uma disciplina em relação à outra eram somente os conteúdos de cada uma delas, pois as orientações metodológicas eram as mesmas, independentemente da especificidade da disciplina.

Mas é preciso apontar que as disciplinas de Língua Portuguesa e de Matemática mereceram destaque, pois, ao longo do período investigado (1971 a 1982), ocorreram cursos específicos para essas duas áreas, tanto para professores de $1^{\mathrm{a}}$ a $4^{\mathrm{a}}$ séries como para professores que atuavam de $5^{\mathrm{a}}$ a $8^{\mathrm{a}}$ séries do $1^{\mathrm{o}} \mathrm{Grau}$. Esses cursos tinham, como já afirmado anteriormente, foco no planejamento e na elaboração de atividades que seguiam uma lógica tecnicista de ensino, ou seja, planejamento rigoroso das etapas da atividade como forma de garantir resultados satisfatórios da aprendizagem dos alunos (COSTA, 2012).

\section{A implantação da reforma do ensino de $2^{\circ}$ grau e a capacitação de recursos humanos}

A implantação da Reforma do Ensino de $2^{\circ}$ Grau ocorreu, em menor proporção, de forma muito semelhante ao ensino de $1^{\circ}$ Grau. Basicamente a abrangência e o planejamento ocorreram em paralelo às ações do processo de implantação da Reforma do Ensino de $1^{\circ}$ Grau, tendo início no ano de 1973 em treze municípios, como projeto piloto, mas é no ano seguinte que se intensificam as ações de capacitação e aperfeiçoamento para os professores que atuavam no $2^{\circ}$ Grau. 
Seguindo o mesmo critério de expansão do Ensino de $1^{\circ}$ Grau, definiram-se os municípios em função do número de habitantes das cidades. Dessa forma, a Expansão do Ensino de $2^{\circ}$ Grau seguiu a seguinte ordem: 1974 com a Expansão I em onze municípios; 1975 com a Expansão II em onze municípios; 1976 com a Expansão III em vinte municípios com população superior a 10 mil habitantes; 1977 com a Expansão IV em trinta e sete municípios com população superior a 8 mil habitantes e sessenta e seis municípios com população inferior a 8 mil habitantes (COSTA, 2012).

Podemos observar que os cursos destinados aos professores do $2^{\circ}$ Grau têm seu início a partir do ano de 1974 e se intensificam no ano de 1977. Após o início da implantação, o cronograma da Expansão II, III e IV sofre um ajustamento devido à falta de recursos humanos habilitados disponíveis para o desenvolvimento das disciplinas que faziam parte da Formação Especial do Currículo de $2^{\circ}$ Grau, como por exemplo, edificações, sanitarismo, eletrotécnica, análise e conservação do solo, comércio, agropecuária e florestal.

Além disso, foram realizados cursos relativos à formação geral, ou seja, para as disciplinas do núcleo comum como Biologia, Química, Física, Língua Portuguesa. Os cursos tinham foco nas orientações metodológicas para o ensino envolvendo a prática de projetos e também de utilização de recursos experimentais para as disciplinas de Química, Biologia e Física.

\section{A capacitação em Educação Especial e Ensino Supletivo}

As modalidades de ensino também foram contempladas no planejamento do CETEPAR e na realização dos cursos de capacitação e aperfeiçoamento. Em relação à Educação ou Ensino Especial a maioria dos cursos é de especialização, com uma carga horária superior a trezentas e oitenta horas que habilitavam os professores a atuarem junto a alunos com necessidades educativas especiais, e os cursos que ocorreram estavam pulverizados ao longo do período definido neste estudo. 
As temáticas desenvolvidas nesses cursos envolviam as áreas de deficiência mental, visual e também problemas relacionados com a audiocomunicação. Os distúrbios de aprendizagem são abordados em um único curso realizado em 1977, e posteriormente há uma atualização nesses mesmos temas no ano de 1978. O que se pode perceber é que a área de Educação Especial contava com uma capacitação em nível de especialização. E, por fim, no ano de 1980 há indícios da realização de um curso em Psicopedagogia, destinado aos professores que atuavam na Educação Especial no Estado do Paraná.

O Ensino Supletivo é instituído como forma de promover a educação do indivíduo que não pode realizá-lo na época que lhe era determinada, ou seja, dar condições de escrita, leitura e o domínio de cálculos aos sujeitos além da idade escolar regular que atuavam como força de trabalho, seja no meio rural, na indústria ou nos canteiros de obras. Não só no Paraná, mas como preocupação do Governo Federal, a educação nessa modalidade exigiu uma ação específica para a organização do processo de ensino e aprendizagem. Dessa forma, os convênios com o governo Estadual e Federal ganharam forma e houve uma capacitação desenvolvida pelo CETEPAR, que utilizou dos referenciais teóricos e metodológicos desenvolvidos pelo Centro de Ensino Técnico de Brasília. Esses referenciais tratam das dimensões legais do Ensino Supletivo, das razões sociais dessa modalidade, da psicologia do adulto e também da metodologia do ensino personalizado.

Os cursos destinados aos professores que atuavam nesta modalidade de ensino foram esparsos, pois ocorreram em períodos isolados como, por exemplo, de 1974 a 1977, em 1980 e 1982. Esses cursos atendiam os professores que atuavam na formação ou no ensino de $1^{\circ}$ e $2^{\circ}$ graus e em curso de formação de Auxiliar de Enfermagem, pois possibilitava a habilitação de indivíduos que já atuavam nessa área, mas que não tinham a formação escolar oficial. 


\section{A supervisão, a execução e a avaliação dos cursos de capacitação e aperfeiçoamento}

Tendo a intenção de atingir os objetivos previstos nos planejamentos da Implantação da Reforma do Ensino de $1^{\circ}$ e $2^{\circ}$ Graus, o acompanhamento, a orientação, o treinamento, a reciclagem e a supervisão das ações de capacitação e aperfeiçoamento eram considerados imprescindíveis. Todo o processo de aperfeiçoamento desenvolvido pelo CETEPAR tinha como ação imediata e sistemática a capacitação de recursos humanos que seriam responsáveis por atuar como multiplicadores, monitores e supervisores executando as ações previstas para a implantação da Reforma do Ensino a partir da Lei no 5.692/71.

Esses cursos previam uma ampla ação de capacitação para a disseminação, controle e avaliação, pois eram destinados aos agentes que seriam responsáveis por executar as ações previstas no Plano Estadual de Ensino junto aos professores na implantação e configuração do novo sistema de ensino e suas modalidades.

Esses "executores" poderiam atuar diretamente nos cursos desenvolvidos, estimulando os professores a utilizarem métodos e técnicas de ensino (multiplicadores e monitores), seja para a zona urbana ou rural, na orientação de professores na escola sobre a Pré-Escola e ensino de $1^{\circ}$ e $2^{\circ}$ Graus, na organização dos estabelecimentos de ensino (considerando os diretores), no cumprimento da Lei no 5.692/71 no tocante à documentação escolar (secretários de escola e técnicos administrativos).

Já os supervisores eram encarregados do acompanhamento das modalidades de Educação/Ensino Especial e também do Supletivo, das metodologias e conteúdos de ensino, do controle do rendimento do sistema, da detecção ou diagóstico de deficiências e sua correção, de modo a implantar um sistema e métodos de ensino mais eficientes para a Educação. 


\section{A concepção pedagógica presente nas ações de capacitação e aperfeiçoamento de professores desenvolvidas pelo \\ CETEPAR}

Ao buscar vestígios de uma concepção de Educação, de ensino e de aprendizagem nos materiais e nos documentos que foram utilizados nos diversos cursos realizados pelo CETEPAR durante o recorte temporal que orientou este estudo, podemos encontrar vários elementos que nos aproximam de uma concepção tecnicista.

Um deles se refere à importância destacada pelos materiais, e que foi veiculada nos cursos, do planejamento do processo de ensino. A seleção de conteúdo, a avaliação e a mensuração deveriam ser metodicamente pensadas e organizadas pelos professores. A concepção de aperfeiçoar, fosse os professores ou os alunos, era claramente expressa nos documentos que tomavam como indício o quantitativo de municípios e professores que foram contemplados pela capacitação e aperfeiçoamento.

É importante ressaltar que um aspecto ficou ausente nessa perspectiva: a realidade do professor, ou seja, na preocupação de o professor assumir o ideário da reforma objetivada pela Lei $n^{\circ} 5.692 / 71$, a realidade do professor, suas necessidades formativas não foram consideradas; assim, o governo estadual desenvolveu ações que foram consideradas ideais a ponto de negligenciar o real, principalmente o contexto do professor e suas condições de trabalho e ensino.

A preocupação com os resultados a serem obtidos reflete na instituição do supervisor e do orientador tanto no âmbito da escola, entendido como local, quanto nos âmbitos regional e estadual para garantir o sucesso das ações planejadas pelo CETEPAR. Outra função que teve uma relação muito estreita com o aperfeiçoamento e capacitação de professores da época foi a de programador, que era diretamente ligada à Gerência de Treinamento do CETEPAR. Essa gerência tinha atribuições relacionadas à elaboração de projetos de aperfeiçoamento, definição de metodologias e de materiais instrucionais, seleção de referenciais teóricos e acompanhamento das avaliações dos cursos desenvolvidos (RODA, 1981). 
As ações do programador, segundo a autora, compreenderam tarefas relacionadas com os cursos de treinamento ofertados pelo CETEPAR: detalhamento da sistemática do projeto, caracterização dos recursos humanos envolvidos nos projetos, elaboração de diretrizes de execução para cada projeto elaborado, acompanhamento da execução dos projetos, previsão de ações de desenvolvimento de recursos humanos para a educação, apontar e definir ações prioritárias para o desenvolvimento de recursos humanos para a educação, reflexão sobre o processo de desenvolvimento de recursos humanos, analisar propostas de treinamento que fossem encaminhadas por outras instituições, elaboração e avaliação do plano anual de cursos de aperfeiçoamento.

Nos cursos havia um aspecto que reforça nossa afirmação de que a perspectiva pedagógica do CETEPAR se aproximava da abordagem tecnicista, pois existia uma sequência organizada dos passos e atividades que deveriam ocorrer; dessa forma, a programação determinava tudo o que deveria ocorrer e ser realizado num tempo definido. Esses cursos de treinamento tinham como intenção o processo de mudança de comportamento do professor, de caráter corretivo com vistas à aquisição de novas habilidades na execução de suas tarefas, principalmente em relação aos princípios contidos na Lei $n^{\circ} 5.692 / 71$.

\section{Considerações finais}

Quando se busca nas fontes os termos destinados aos cursos desenvolvidos no período de 1971 a 1982, observamos uma diversidade de termos, pois em alguns registros encontramos atualização, capacitação, treinamento e também aperfeiçoamento. Independentemente de os conceitos apresentarem certas variações, no caso do Paraná todos esses termos serviram para denominar as ações que tinham como propósito difundir a Reforma do Ensino, inicialmente aos professores do $1^{\circ}$ Grau dos grandes centros urbanos do Estado até, posteriormente, como uma ação progressiva, os cursos atingirem os professores do $2^{\circ} \mathrm{Grau}$, das modalidades de ensino das regiões urbanas e da zona rural e distritos.

Diante dos resultados obtidos, o CETEPAR empreendeu uma mudança conceitual e pedagógica nas ações de aperfeiçoamento. Essa mudança se deu pela 
adoção de um método denominado "eclético", ou seja, "deu-se importância tanto à documentação (processo dedutivo) quanto às vivências dos cursistas (método indutivo)".

Mesmo adotando uma abordagem que possibilitasse uma maior incidência dos cursos sobre a realidade e as necessidades dos professores e seu cotidiano, ainda existia uma forte tendência em conduzir e controlar todo o processo. Os multiplicadores passam a ser denominados de explicitadores, ou seja, eram responsáveis por explicitar os conteúdos e a mensagem presente nos documentos. Esses conteúdos ainda eram organizados e elaborados pelos técnicos do CETEPAR.

A partir das fontes foi possível identificar a predominância da tendência tecnicista nas ações desenvolvidas pelo CETEPAR. Nesse período a ideia de tratar a realidade como um todo integrado faz com que a capacitação e aperfeiçoamento sejam estendidos aos professores dos Distritos e Zona Rural, de classes multisseriadas e de escolas consolidadas. Tudo isso muito alinhado com as pesquisas realizadas sobre o desempenho desses professores.

A análise apresentada nos revela que o CETEPAR cumpriu com o propósito de favorecer a capacitação e o aperfeiçoamento dos professores paranaenses. Ressalta-se também a intenção de um trabalho descentralizado que pudesse atender todo o contingente de professores ligados ao ensino público estadual. Enfatizamos também a abrangência dos diferentes níveis de ensino e, igualmente, das diferentes modalidades de educação presentes no Sistema Estadual de Ensino do Estado do Paraná. Mas, como a realidade é diversa e contraditória, é necessário apontar os conflitos e as controvérsias que permearam as ações de capacitação e aperfeiçoamento desenvolvidas pelo CETEPAR.

Ao propor a descentralização dos cursos de capacitação para as diversas regiões do estado por meio dos Núcleos Regionais de Educação e das Inspetorias Regionais de Ensino, o grupo responsável pela programação não considerou a diferença existente entre os contextos, e os cursos eram multiplicados da mesma forma em todas as localidades. Num primeiro momento a condução na realização dos cursos não mostrou indícios de problemas, mas, com a avaliação, houve a necessidade de adotar outra metodologia que não fosse a da instrução programada, que se mostrou ineficiente. 
Os níveis de ensino são contemplados a partir do momento em que se fez necessária a Implantação da Reforma do Ensino de $1^{\circ}$ e $2^{\circ}$ graus. Toda a capacitação estava voltada, inicialmente, para a inculcação dos fundamentos e referenciais que subsidiaram a implantação da Lei no 5.692/71 e, como reflexo de uma concepção de menos investimento e mais resultados, os cursos foram planejados e programados com base em levantamentos estatísticos.

A excessiva preocupação com o controle e resultados esperados das ações de implantação da reforma engessaram os cursos desenvolvidos pelos multiplicadores, tinham a ação supervisora como controle rígido para que o planejamento não sofresse desvios ou alterações e, consequentemente, houvesse a manutenção de seus propósitos e objetivos.

Sobre esse aspecto, é preciso ressaltar que a implantação da reforma segue uma lógica que discrimina os indivíduos que se encontram em localidades com população inferior a 2 mil pessoas, pois essas passam ter acesso aos cursos somente em 1975, três anos depois que o projeto piloto teve seu início.

Mesmo considerando que a implantação não tenha ocorrido de forma adequada, no sentido de atingir todos os municípios num mesmo momento, deixando parte do professorado à margem das ações iniciais de reforma do ensino, é importante considerar que, mesmo sob uma concepção da época de educação, o Centro de Seleção e Treinamento e Aperfeiçoamento de Pessoal do Paraná cumpriu com o papel de levar aos professores da época uma formação que em muitas regiões do estado era inexistente, ou seja, proporcionou a muitos professores o contato com fundamentos e teorias que estavam ausentes da sua atuação como professor. De maneira alguma estamos justificando as ações que o CETEPAR realizou por não existir outras formas de capacitação e aperfeiçoamento; o que estamos enfatizando é que, para muitos que nunca foram "enxergados" pelo governo estadual, o CETEPAR pela primeira vez acolheu e considerou esses professores como sujeitos atuantes no sistema de ensino estadual.

Nesse sentido, podemos considerar o CETEPAR uma instituição promotora de formação e que, durante um período superior a uma década, foi responsável por pensar, planejar, sistematizar, subsidiar, desenvolver, acompanhar e avaliar os processos de capacitação no estado do Paraná e certificar os professores paranaenses. 


\section{Referências}

CERTEAU, M. A escrita da história. Rio de Janeiro: Forense Universitária, 1988.

COSTA, R. R. A capacitação e aperfeiçoamento de professores que ensinavam matemática no estado do Paraná 1971-1982. In: SEMINÁRIO NACIONAL DE ESTUDOS E PESQUISAS: "História, Sociedade e Educação no Brasil"; 9., 2012, João Pessoa. Anais... João Pessoa: Universidade Federal da Paraíba, 2012. p. 4787-4811.

FÉLIX, L. O. História e memória: a problemática da pesquisa. Passo Fundo: Ediupf, 1998.

FUNDAÇÃO DE APOIO A EDUCAÇÃO PARANAENSE (FUNDEPAR). Análise preliminar dos dados básicos sobre a evolução do ensino regular na rede estadual de ensino 1971-1980. Curitiba: Governo do Estado do Paraná, 1982.

LOPES, E. M. T. Perspectivas históricas da educação. São Paulo: Ática, 1995.

PARANÁ. Secretaria de Estado da Educação. Gênese Pedagógica do CETEPAR. Curitiba, 1977.

PARANÁ. Secretaria do Estado da Educação. Relatório de Atividades 79/83. Curitiba, 1983.

RODA, M. L. Atribuição do programador que atua em agências de desenvolvimento de recursos bumano para a educação. 1981. Dissertação de Mestrado (Mestrado em Educação) - Setor de Educação, Universidade Federal do Paraná, Curitiba, 1981.

VALENTE, W. R. História da Educação Matemática: interrogações metodológicas. Lisboa, 2005a. (Mimeo).

VALENTE, W. R. Filósofos e história da filosofia, pedagogos e bistória da educação matemática e história da matemática: as muitas histórias não-históricas. Trabalho apresentado no Seminário Nacional de História da Matemática, Brasília, 2005b. (Mimeo). 